\title{
Protective Effect of Salep on Liver
}

\author{
Morteza Pourahmad ${ }^{1}$; Hossein Kargar Jahromi ${ }^{2,}$; ${ }^{*}$ ahra Kargar Jahromi ${ }^{2}$ \\ ${ }^{1}$ Infectious Diseases Department, Isfahan University of Medical Sciences, Isfahan, IR Iran \\ ${ }^{2}$ Parasitology Department, Zoonoses Research Center, Jahrom University of Medical Sciences, Jahrom, IR Iran \\ *Corresponding Author: Hossein Kargar Jahromi, Research Center,Jahrom University of Medical Sciences, Jahrom, IR Iran. Tel:+98-9399711845, E-mail: hossein.kargarjahromy@yahoo.com
}

Received: February 21, 2015; Revised: March 26, 2015; Accepted: April 5, 2015

\begin{abstract}
Background: Salep is used for various purposes in food industries and traditional medicine. Therefore, evaluation of its effect on the liver seems to be necessary.

Objectives: The aim of this study was to assess salep effect on liver.

Materials and Methods: In this experimental study, various concentrations of Salep were intraperitoneally administered to five groups of Wistar rats (control, placebo and 20,40 and $80 \mathrm{mg} / \mathrm{kg}$ salep).After one month, liver enzymes and liver tissue were evaluated and compared between different groups.

Results: Significant decreased level of liver enzymes, MDA (Malondialdehyde) and TOC (Total Oxidation Capacity) were found in various concentrations of salep administration. On the other hand, a significant increase was found in TAC (Total Antioxidant Capacity) level with various doses of salep.

Conclusions: Elevated level of total protein and albumin and decreased level of liver enzyme by salep extract were found in this study. Therefore, this plant may be a useful medicine for patients with liver diseases.

Keywords: Rat; Liver; Enzymes; Salep
\end{abstract}

\section{Background}

Salep or Lancibracteata is from orchid family (Orchidaceae) and has various species worldwide. This plant grows in the first days of summer and used for various attempt (1, 2 ). It is used in traditional medicine and food engineering. Nitrogenic materials, glucose, protein, ferolic acid, Quercetin, daucosterol, cirsiliol, steroids and glucomannan are some materials found in Salep $(3,4)$. This plant is used in preparation of drinks, confections and ice cream. On the other hand, it is used as a traditional medicine in various countries including Iran. In traditional medicine, it is used for the treatment of diarrhea, cough and impotency $(5,6)$. There is a belief in people that herbal drugs have no adverse effect. Nevertheless, we know that some herbal drugs may cause some adverse effects in some organs, especially liver and kidneys. A systematic review in Korea presented the possibility of increased risk of hepatotoxicity by administration of some herbal drugs (7). Despite the fact, some studies showed that some plants may have protective effect for liver such as Garlic in nonalchoholic steatohepatitis (NASH) (8), or Aubutilon indicum in paracetamol induced hepatotoxicity (9). Considering that Salep is widely used in some communities, evaluation of the effects of this plant on liver seems to be necessary.

\section{Objectives}

The aim of this study was to assess the effect of salep on liver for the first time.

\section{Materials and Methods}

\subsection{Collection and Extraction of the Plant}

Samples of the plant harvested from farmlands around Yasouj (a city in the southwest of Iran) were obtained. The roots of the plant washed and dried in the laboratory (away from direct light of sun). Then the dried roots ground into flour by electric mill. The powder mixed by ethylic alcohol in 1 to 5 proportions and mixed for 24 hours to yield a uniform solution. In the next stage, the solution filtered and dried for 48 hours to yield the solid extract without alcohol. The final extract mixed with distilled water in 20,40 and $80 \mathrm{mg} / \mathrm{mL}$ and maintained in refrigerator (10).

\subsection{Animals and Grouping Them}

This study was an experimental study on Wistar rats. In this study, all the ethic points in working by animals were considered in all steps. The proposal of this study was approved in the research ethic committee of Jahrom University of Medical Sciences. In this study, 50 Wistar rats weighting 180 to 200 grams were used. Before starting the study, rats cared in animal house in Jahrom University of Medical Sciences for adaptation to environment. During the study, these animals were in 12 hours light and 12 hours darkness with temperature of $20-25^{\circ} \mathrm{C}$. They had access to water and food ad libitum. We randomly di-

Copyright (C) 2015, Kowsar Corp. This is an open-access article distributed under the terms of the Creative Commons Attribution-NonCommercial 4.0 International License (http://creativecommons.org/licenses/by-nc/4.0/) which permits copy and redistribute the material just in noncommercial usages, provided the original work is properly cited. 
vided the animals into five groups each with 10 rats. The first group underwent no intervention; the second group received $1 \mathrm{~mL}$ distilled water intraperitoneally daily, each rat in 3rd, 4th and 5th groups received 20, 40 and $80 \mathrm{mg} /$ $\mathrm{kg}$ prepared hydroextract, respectively daily. This was continued for 29 days.

\subsection{Evaluation of Liver Function Tests}

In 29th day of study, blood tests for liver function were performed. For this purpose after anesthesia, $5 \mathrm{~mL}$ blood received from each rat and after centrifugation in 3000 $\mathrm{r} / \mathrm{m}$ for 15 minutes serum was separated and used for tests (11). The levels of ALT (Alanine aminotransferase) and AST (Aspartate aminotransferase) were measured by DGKC buffer phosphate method and the level of ALP (Alkaline phosphatase) measured by $\rho$-Nitrophenyl phosphate AMP. Serum albumin and total bilirubin and total protein were measured by the methods of Bromocresol Green, Diazo with sulphanilic acid, and Biuret reaction end point, respectively. The level of MAD was evaluated by ELISA method (Biospes Italy) and the levels of TAC and TOC were also measured by ELISA (LDN Italy) (12).

\subsection{Tissue Evaluation}

After drawing the blood, liver was separated, weighted and fixed by formalin solution. Tissue samples were prepared and evaluated by microscope. Statistical analysis was performed using SPSS software (IBM) and P value below 0.05 considered to be significant.

\section{Results}

Liver enzymes evaluation; the levels of AST, ALT and ALP significantly decreased with administration of higher doses of salep ( $80 \mathrm{mg} / \mathrm{kg}$ ). This effect was found in bilirubin MDA and TOC levels. On the other hand, it seems that with administration of salep the level of total serum protein and albumin elevated, especially with the highest dose. This effect was also shown in TAC level (Table 1).

\subsection{The Effect of Salep on Liver Tissue}

Pathology of liver tissue evaluated and there was no sign of edema, irregularity of the hepatocells, vein engorgement, necrosis, accumulation of kupfer cells, change in portal area and infiltration of inflammatory cells. In short, no significant effect on liver tissue was revealed by various doses $(20,40$, or $80 \mathrm{mg} / \mathrm{kg}$ ) of salep (Figure 1 ).

\section{Discussion}

Injection of salep extract could decrease the level of liver function enzymes including AST, ALT and ALP. In liver damage, the level of these enzymes would be increased(13). This effect maybe due to the presence of anti-oxidant material in

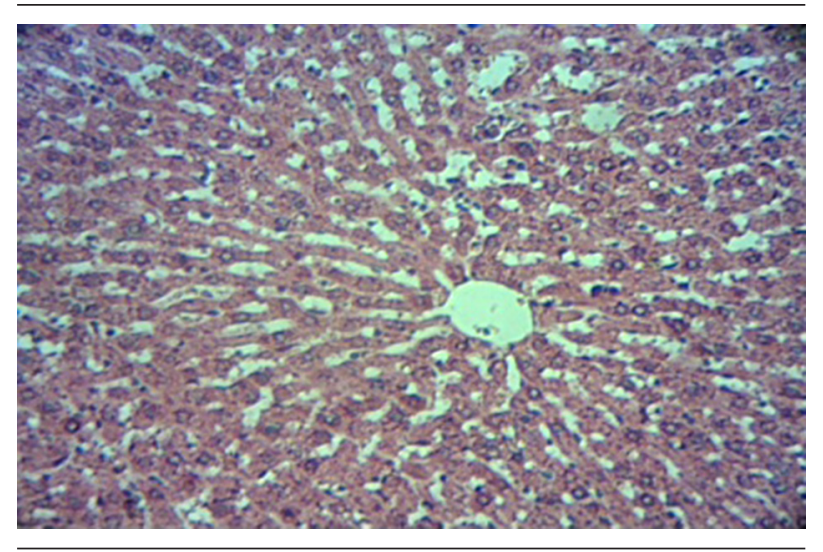

Figure 1. Microscopic View of the Liver Tissue in Studied Group (80 mg/ $\mathrm{kg}),(\mathrm{H} \& \mathrm{E} \times 100)$

\begin{tabular}{|c|c|c|c|c|c|}
\hline Parameter & Control & Distilled Water & Salep, $20 \mathrm{mg} / \mathrm{kg}$ & Salep, $40 \mathrm{mg} / \mathrm{kg}$ & Salep, $80 \mathrm{mg} / \mathrm{kg}$ \\
\hline AST, IU/L & $93 \pm 2.57$ & $93.57 \pm 2.30$ & $87.71 \pm 3.53$ & $85 \pm 2.94$ & $76.14 \pm 1.68$ \\
\hline ALT, IU/L & $47.85 \pm 1.26$ & $42.28 \pm 0.81$ & $45.57 \pm 1.04$ & $43.42 \pm 0.87$ & $39.85 \pm 0.96$ \\
\hline ALP, IU/L & $485.42 \pm 30.69$ & $490 \pm 29.27$ & $432.57 \pm 19.13$ & $415.28 \pm 15.29$ & $343.71 \pm 22.62$ \\
\hline Total protein, g/dL & $6.31 \pm 0.06$ & $6.41 \pm 0.03$ & $6.37 \pm 0.10$ & $6.3 \pm 0.04$ & $7.44 \pm 0.06$ \\
\hline Albumin, $\mathbf{g} / \mathbf{d L}$ & $3.18 \pm 0.09$ & $3.19 \pm 0.07$ & $3.25 \pm 0.11$ & $3.36 \pm 0.10$ & $4.04 \pm 0.06$ \\
\hline Total bilirubin, $\mathrm{Mg} / \mathrm{dL}$ & $1.01 \pm 0.05$ & $1.02 \pm 0.04$ & $0.97 \pm 0.03$ & $0.91 \pm 0.04$ & $0.88 \pm 0.04$ \\
\hline TAC, $\mathbf{U} / \mathbf{m L}$ & $1.5 \pm 0.05$ & $1.53 \pm 0.08$ & $1.74 \pm 0.05$ & $2.96 \pm 0.10$ & $3.56 \pm 0.11$ \\
\hline TOC, $\mathbf{U} / \mathbf{m L}$ & $2.36 \pm 0.15$ & $2.33 \pm 0.15$ & $2.16 \pm 0.02$ & $1.96 \pm 0.03$ & $1.8 \pm 0.04$ \\
\hline MDA, Nmol/L & $0.12 \pm 0.01$ & $0.13 \pm 0.01$ & $0.11 \pm 0.02$ & $0.08 \pm 0.01$ & $0.05 \pm 0.01$ \\
\hline
\end{tabular}

a Abbreviations: ALT, Alanine Transferase;ALP,Alkaline phosphatase; AST, Aspartate Transferase; g/dL, gram per deciliter; IU/L, Internation Unit Per Liter; MDA, Malondialdehyde; TAC, Total Antioxidation Capacity; and TOC, Total oxidation Capacity.

b p value below 0.05 was considered as significant. There was no significant statistical difference between the levels. 
this plant. Polyphenols and flavonoid components such as Quercetin are important anti-oxidants in this plant (14). These components have protective effect on the liver against toxins and free radicals $(15,16)$. Ferolic acid is another strong antioxidant in salep extract $(3,4)$. It is shown that ferolic acid has protective effect for liver against toxic materials such as alcohol and high fat foods. In these studies it was shown that ferolic acid can effectively reduce the level of ALT, AST and ALP in rats, which received alcohol and high fat foods (17). Glucomannan is a fiber, which is water soluble and can inhibit stress oxidation and reduce AST and ALT levels $(18,19)$. This component is present in salep $7 \%$ to $61 \%$ in various species. This fiber is also effective on reducing the blood sugar, cholesterol and body weight $(20,21)$. One of the signs of progression of chronic liver disease is decreased level of total protein and albumin. The level of this deduction is proportionate with the severity of liver damage $(22,23)$. In this study, we showed that the level of total protein and albumin could be elevated by salep. This elevation is significant with higher doses of salep. Therefore, we can say that this plant can have protective effect for liver. This effect is also shown for MAD, TOC and TAC in this study. MAD is one of the important criteria for lipid peroxidation and is an indicator for liver damage (24). TAC (Total Antioxidant Capacity) is a better criterion than GPX, CAT and SOD for evaluating the antioxidation condition in the body (25), this capacity has a reverse correlation with TOC (26). Augmentation of TAC and reduction of TOC and MAD by salep may be due to antioxidants in this plant. Polyphenols and flavonoids in this plant can protect cells against diminution of reduced glutathione. This action is performed by elevation of antioxidative enzymes such as glutathione, glutathione reductase, glutathione peroxidase and catalase (27). Reduced glutathione can diminish the oxidized form of glutathione peroxidase, which in turn can diminish hydrogen peroxide $(\mathrm{H} 2 \mathrm{O} 2)$ as a dangerous reactive component within the cell. Glucomannan can modulate the antioxidant system capacity. This component can elevate the level of SOD (supper oxide dismutase) and catalase enzymes. It also can decrease the MAD level in liver (28). In conclusion, salep may have a protective effect on liver in animal models and more studies are needed to evaluate its effect in human.

\section{Acknowledgements}

We would like to thank the vice chancellor of research of Jahrom University of Medical Sciences and Dr. Raoofi for his special support.

\section{Authors' Contributions}

Morteza Pourahmad: corresponding author and designing the study. Hossein Kargar Jahromi: design and performing the study. Zahra Kargar Jahromi: performing the study.

\section{Funding/Support}

This study was supported by Jahrom University of Medical Sciences, Jahrom, IR Iran.

\section{References}

1. Freudenstein JV, Rasmussen FN. Sectile pollinia and relationships in theOrchidaceae. Plant Syst Evol.1997;205(3-4):125-46.

2. Cozzolino S, Widmer A. Orchid diversity: an evolutionary consequence of deception? Trends Ecol Evol. 2005;20(9):487-94.

3. Barone Lumaga MR, Cozzolino S, Kocyan A. Exine micromorphology of Orchidinae (Orchidoideae, Orchidaceae): phylogenetic constraints or ecological influences? Ann Bot. 2006;98(1):237-44.

4. Grieve M. A modern herbal the medicinal, culinary, cosmetic and economic properties, cultivation and folk- lore of herbs, grasses, fungi, shrubs and trees with their modern scientific uses.New York; 1989.

5. Kaya S, Tekin AR. The effect of salep content on the rheological characteristics of a typical ice-cream mix. J Food Eng. 2001;47(1):59-62.

6. Farhoosh R, Riazi A. A compositional study on two current types of salep in Iran and their rheological properties as a function of concentration and temperature. Food Hydrocoll. 2007;21(4):660-6.

7. Oh SJ, Cho JH, Son CG. Systematic review of the incidence of herbal drug-induced liver injury in Korea. J Ethnopharmacol. 2015;159:253-6.

8. Wu ZR, Peng C, Yang L, Li JY, Xin W, Yong W, et al. Two cinnamoyloctopamine antioxidants from garlic skin attenuates oxidative stress and liver pathology in rats with non-alcoholic steatohepatitis. Phytomedicine. 2015;22(1):178-82.

9. Porchezhian E, Ansari SH. Hepatoprotective activity of Abutilon indicum on experimental liver damage in rats. Phytomedicine. 2005;12(1-2):62-4.

10. Faraji Z, Nikzad H, Parivar K, Nikzad M. The effect of aqueous extract of Salep Tubers on the structure of testis and sexual hormones in male mice. JJahrom Univ Med Sci. 2013;11(1):62.

11. Mohajeri D, Mesgari Abbasi M, Delazar A, Doustar Y, Mousavi G, Amouoghli Tabrizi B. Histopathological study of subacute toxicity of Crocus sativus L.(Saffron) stigma total extract on liver and kidney tissues in the rat. Pharmaceut Sci. 2009;15(2):115-24.

12. Mostafavi-Pour Z, Zal F, Monabati A, Vessal M. Protective effects of a combination of quercetin and vitamin $\mathrm{E}$ against cyclosporine A-induced oxidative stress and hepatotoxicity in rats. Hepatol Res. 2008;38(4):385-92.

13. Giannini EG, Testa R, Savarino V. Liver enzyme alteration: a guide for clinicians. CMAJ. 2005;172(3):367-79.

14. Chen JW, Zhu ZQ, Hu TX, Zhu DY. Structure-activity relationship of natural flavonoids in hydroxyl radical-scavenging effects. Acta Pharmacol Sin. 2002;23(7):667-72.

15. Areias FM, Valentao P, Andrade PB, Ferreres F, Seabra RM. Phenolic fingerprint of peppermint leaves. Food Chem. 2001;73(3):307-11.

16. Perez-Carreon JI, Cruz-Jimenez G, Licea-Vega JA, Popoca EA, Fazenda SF, Villa-Trevino S. Genotoxic and anti-genotoxic properties of Calendula officinalis extracts in rat liver cell cultures treated with diethylnitrosamine. Toxicol In Vitro. 2002;16(3):253-8.

17. Rukkumani R, Aruna K, Suresh Varma P, Padmanabhan Menon V. Hepatoprotective role of ferulic acid: a dose-dependent study. $J$ Med Food. 2004;7(4):456-61.

18. Donmez N, Keskin E. The effects of aflatoxin and glucomannan on some antioxidants and biochemical parameters in rabbits. Acta Vet. 2008;58(4):307-13.

19. Dvorska JE, Pappas AC, Karadas F, Speake BK, Surai PF. Protective effect of modified glucomannans and organic selenium against antioxidant depletion in the chicken liver due to T-2 toxin-contaminated feed consumption. Comp Biochem Physiol C Toxicol Pharmacol. 2007;145(4):582-7.

20. Tekinsen KK, Guner A. Chemical composition and physicochemical properties of tubera salep produced from some Orchidaceae species. Food Chemistry. 2010;121(2):468-71.

21. Machessault R. Structural studies on triactates of mannan and glucomannan carbohydrate. Polym. 1981;1(2):129-38.

22. Sethuraman MG, Lalitha KG, Rajkapoor B. Hepatoprotective ac- 


\section{Kargar Jahromi H et al.}

tivity of Sarcostemma brevistigma against carbon tetrachlorideinduced hepatic damage in rats. Curr Sci. 2003;84:22-7.

23. Jayasekhar P, Mohanan PV, Rathinam K. Hepatoprotective activity of ethyl acetate extract of Acacia catechu. Indian J Pharmacol. 1997;29(6):426.

24. Ostad Rahimi A, Mahdavi R, Somi MH, Tarzemani MK. Oxidative stress-related parameters and antioxidant status in nonalcoholic fatty liver disease patients. Iran J Endocrinol Metab. 2011;12(5):493-9.

25. Madan K, Bhardwaj P, Thareja S, Gupta SD, Saraya A. Oxidant stress and antioxidant status among patients with nonalcoholic fatty liver disease (NAFLD). J Clin Gastroenterol . 2006;40(10):930-5.

26. Atakisi O, Erdogan HM, Atakisi E, Citil M, Kanici A, Merhan O, et al Effects of reduced glutathione on nitric oxide level, total antioxidant and oxidant capacity and adenosine deaminase activity. Eur Rev Med Pharmacol Sci. 2010;14(1):19-23.

27. Chu YF, Sun J, Wu X, Liu RH. Antioxidant and antiproliferative activities of common vegetables. J Agric Food Chem 2002;50(23):6910-6.

28. Wu WT, Chen HL. Konjac glucomannan and inulin systematically modulate antioxidant defense in rats fed a high-fat fiber-free diet. J Agric Food Chem. 2011;59(17):9194-200. 